International Journal of Engineering, Science and Technology

Vol. 2, No. 2, 2010, pp. 174-190
INTERNATIONAL

JOURNAL OF

ENGINEERING,

SCIENCE AND

TECHNOLOGY

www.ijest-ng.com

(C) 2010 MultiCraft Limited. All rights reserved

\title{
Persistence and stability of a two prey one predator system
}

\author{
T. K. Kar ${ }^{a^{*}}$ and Ashim Batabyal ${ }^{\mathrm{b}}$ \\ ${ }^{a}$ Department of Mathematics, Bengal Engineering and Science University, Shibpur, Howrah-711103, INDIA \\ ${ }^{b}$ Department of Mathematics, Bally Nischinda Chittaranjan Vidyalaya, Bally Ghoshpara, Howrah, INDIA \\ E-mails:(tkar1117@gmail.com, T. K. Kar), "Corresponding author); ashim.bat@gmail.com (Ashim Batabyal)
}

\begin{abstract}
The purpose of this work is to offer some mathematical analysis of the dynamics of a two prey one predator system in the presence of a time delay due to gestation. We derived criteria which guarantee the persistence of the three species and the global dynamics of the model system. Our study also shows that, the time delay may play a significant role on the stability of the system. Lastly, some numerical simulations are given to illustrate analytical results.
\end{abstract}

Keywords: Prey predator, persistence, extinction, global stability, Hopf bifurcation.

AMS Subject classifications: 34C07, 34D23, 92D25.

\section{Introduction}

The dynamic relationship between predators and their prey has long been and will continue to be one of the dominant themes in both ecology and mathematical ecology due to its universal existence and importance. Over the past decades, mathematics has made a considerable impact as a tool to model and understand biological phenomena. In return, biologists have confronted the mathematicians with a variety of challenging problems, which have stimulated developments in the theory of nonlinear differential equations. Such differential equations have long played important role in the field of theoretical population dynamics, and they will, no doubt, continue to serve as indispensable tools in future investigations. Differential equation models for interactions between species are one of the classical applications of mathematics to biology. The development and use of analytical techniques and the growth of computer power have progressively improved our understanding of these types of models. Although the predator-prey theory has seen much progress, many long standing mathematical and ecological problems remain open.

Theoretical ecology remained silent about the astonishing array of dynamical behaviors of three species models for a long time. Of course, the increasing number of differential equations and the increasing dimensionality raise considerable additional problems both for the experimentalist and theoretician. Freedman and Waltman (1984) considered three level food webs - two competing predators feeding on a single prey and a single predator feeding on two competing prey species. They obtain criteria for the system to be persistent. Kar and Chaudhuri (2004) considered a two-prey one-predator harvesting model with interference. The model is based on Lotka-Volterra dynamics with two competing species which are affected not only by harvesting but also by the presence of a predator, the third species. Optimal harvesting policy and the possibility of existence of a bioeconomic equilibrium is discussed. Dubey and Upadhyay (2004) proposed a two predator one prey system with ratio dependent predator growth rate. Criteria for local stability, instability and global stability of the non-negative equlibria are obtained. They also discussed about the permanent co-existence of the three species. Braza (2008) considered a two predator; one prey model in which one predator interferes significantly with the other predator is analyzed. The analysis centers on bifurcation diagrams for various levels of interference in which the harvesting is the primary bifurcation parameter. Zhang et al. (2006) studied the stability of three species population model consisting of an endemic prey (bird), an alien prey (rabbit) and an alien predator (cat).

It may be pointed out here that all the above studies are based on the traditional prey dependent models. Recently, it has been observed that in some situations, especially when a predator have to search for food and have two different choice of food, a more suitable predator-prey theory should be based on the so-called ratio-dependent theory, in which the per-capita growth rate should be function of the ratio of prey to predator abundance, and should be the so-called predator functional response (Abrams and Ginzburg, 2000; Akcakaya et al., 1995; Arditi et al., 1991; Arditi and Saiah, 1992). 
Recently, Kesh et al. (2000) proposed and analyzed a mathematical model of two competing prey and one predator species where the prey species follow Lotka-volterra dynamics and predator uptake functions are ratio dependent. They derived conditions for the existence of different boundary equilibria and discussed their global stability. They also obtain sufficient conditions for the permanence of the system. Hsu et al. (2001) studied the qualitative properties of a ratio dependent predator-prey model. They showed that the dynamics outcome of interactions depend upon parameter values and initial data.

Three general forms of functional response are commonly used in ecological models: linear, hyperbolic, and sigmoidal. How predators respond to changes in prey availability (functional response) is an issue of particular importance. There is evidence from several models that the type of functional response specified can greatly affect model predictions (Gao et al., 2000; Kar and Chaudhury, 2004).

To have a perfect model we would need to consider so many factors, namely, growth rate, death rate, carrying capacity, stage structure, predation rate, stochasticity etc. However, it is obvious that a perfect model can not be achieved because even if we could put all these factors in a model, the model could never predict ecological catastrophes of Mother Nature caprice. Therefore, the best we can do is to look for analyzable model that describes as well as possible the reality.

In this paper, we shall study the dynamical behaviors of a two prey one predator system. Before we introduce the model and its analysis we would like to present a brief sketch of the construction of the model which may indicate the biological relevance of it.

(i) There are three populations namely, two prey whose population densities are $\mathrm{x}$ and $\mathrm{y}$, the predator whose population density is denoted by $\mathrm{z}$.

(ii) In the absence of the predator the prey population density grows according to logistic law of growth.

(iii) Two prey species are competitive in nature.

(iv) One prey is much higher in abundance and more vulnerable compare to other.

(v) Handling time for one prey is negligible, where as the predator needs sufficient handling time for other prey. These are incorporated using Holling type I and II functional response.

(vi) There is a reaction time for predator.

On the basis of the above assumptions, our proposed model is as follows:

$$
\begin{aligned}
& \frac{d x}{d t}=r x\left(1-\frac{x}{K}\right)-a_{1} x y-\omega_{1} x z, \\
& \frac{d y}{d t}=s y\left(1-\frac{y}{L}\right)-a_{2} x y-\frac{\omega_{2} y z}{(m+y)}, \\
& \frac{d z}{d t}=b_{1} \omega_{1} x(t-\tau) z+b_{2} \omega_{2} \frac{y(t-\tau) z}{m+y(t-\tau)}-c z .
\end{aligned}
$$

In model (1), $\mathrm{r}$ and $\mathrm{s}$ are the intrinsic growth rate of two prey species, $\mathrm{K}$ and $\mathrm{L}$ are their carrying capacities, $\mathrm{c}$ is the mortality rate coefficient of the predator, $a_{1}, a_{2}$ are inter-species interference coefficient of two prey species, $\omega_{1}$ is the first prey specie's searching efficiency and $\omega_{2}$ is the second type prey specie's searching efficiency of the predator, $b_{1}$ and $b_{2}$ are the conversion factors denoting the number of newly born predators for each captured of first and second prey respectively, and $\mathrm{m}$ is the half saturation co-efficient. A discrete time delay $(\tau \geq 0)$ is introduced to the functional response term involved with the growth equation of predator to allow for a reaction time (Liu, 1994).

Section 2 deals with the determination of plausible steady states and their existence conditions. Dynamical behavior of these steady states is discussed in section 3. Global stability and persistence of the system is studied in section 4 . Section 5 deals with simulation and discussion of the problem.

\section{Equilibrium analysis}

It can be checked that the system (1) has seven non-negative equilibria and three of them namely $\mathrm{E}_{\mathrm{o}}(0,0,0), \mathrm{E}_{\mathrm{x}}(\mathrm{K}, 0,0), \mathrm{E}_{\mathrm{y}}(0$, $\mathrm{L}, 0)$ always exist. We show the existence of other equilibria as follows:

Existence of $\mathbf{E}_{\mathbf{x y}}\left(\mathbf{x}_{4}{ }^{*}, \mathbf{y}_{4}{ }^{*}, 0\right)$

Here $\mathrm{x}_{4}{ }^{*}, \mathrm{y}_{4}{ }^{*}$ are the positive solution of the following algebraic equations.

$$
r\left(1-\frac{x}{K}\right)-a_{1} y=0, s\left(1-\frac{y}{L}\right)-a_{2} x=0
$$

Solving (2), we get 


$$
x_{4}^{*}=\frac{s K\left(r-a_{1} L\right)}{r s-a_{1} a_{2} K L}, y_{4}^{*}=\frac{r L\left(s-a_{2} K\right)}{r s-a_{1} a_{2} K L}
$$

Thus, the equilibrium $\mathrm{E}_{\mathrm{xy}}\left(\mathrm{x}_{4}{ }^{*}, \mathrm{y}_{4}{ }^{*}, 0\right)$ exists if $\left(r-a_{1} L\right)$ and $\left(s-a_{2} K\right)$ are of same sign, that is either

$r>a_{1} L$ and $s>a_{2} K$

Or, $r<a_{1} L$ and $s<a_{2} K$

Existence of $\mathbf{E}_{\mathbf{y z}_{*}}\left(0, \mathbf{y}_{5}{ }^{*}, \mathbf{z}_{5}{ }^{*}\right)$

Here $\mathrm{y}_{5}{ }^{*}, \mathrm{z}_{5}{ }^{*}$ are the positive solution of the following algebraic equations.

$$
s\left(1-\frac{y}{L}\right)-\frac{\omega_{2} z}{m+y}=0, \frac{b_{2} \omega_{2} y}{m+y}-c=0 .
$$

Solving (5), we get

$$
y_{5}^{*}=\frac{c m}{b_{2} \omega_{2}-c} \text { and } z_{5}^{*}=\frac{s}{\omega_{2}}\left(1-\frac{y_{5}^{*}}{L}\right)\left(m+y_{5}^{*}\right)
$$

It can be seen that $\mathrm{E}_{\mathrm{yz}}\left(0, \mathrm{y}_{5}{ }^{*}, \mathrm{z}_{5}{ }^{*}\right)$ exists if

$$
L\left(b_{2} \omega_{2}-c\right)>c m \text {. }
$$

Existence of $\mathbf{E}_{\mathbf{x z}}\left(\mathbf{x}_{\mathbf{6}}{ }^{*}, \mathbf{0}, \mathbf{z}_{\mathbf{6}}{ }^{*}\right)$

Here $\mathrm{x}_{6}{ }^{*}, \mathrm{z}_{6}{ }^{*}$ are the positive solution of

$$
r\left(1-\frac{x}{K}\right)-\omega_{1} z=0, b_{1} \omega_{1} x-c=0 .
$$

Solving (8), we get

$$
x_{6}^{*}=\frac{c}{b_{1} \omega_{1}}, z_{6}^{*}=\frac{r}{\omega_{1}}\left(1-\frac{c}{K b_{1} \omega_{1}}\right)
$$

It can be seen that $\mathrm{E}_{\mathrm{xz}}\left(\mathrm{x}_{6}{ }^{*}, 0, \mathrm{z}_{6}{ }^{*}\right)$ exists if

$$
K b_{1} \omega_{1}>c \text {. }
$$

Existence of $\mathbf{E}_{\mathbf{x y z}}\left(\mathbf{x}_{7}{ }^{*}, \mathbf{y}_{7}{ }^{*}, \mathbf{z}_{7}{ }^{*}\right)$

Here $\left(x_{7}{ }^{*}, y_{7}{ }^{*}, z_{7}{ }^{*}\right)$ is the positive solution of the system of algebraic equations given below:

$$
\begin{aligned}
& r\left(1-\frac{x}{K}\right)-a_{1} y-\omega_{1} z=0, \\
& s\left(1-\frac{y}{L}\right)-a_{2} x-\frac{\omega_{2} z}{m+y}=0, \\
& b_{1} \omega_{1} x+b_{2} \omega_{2} \frac{y}{m+y}-c=0 .
\end{aligned}
$$

Solving (11a) \& (11b), we get

$$
f(y, z)=0 \text {, }
$$

where

$f(y, z)=r K a_{2} L(m+y)-r s(L-y)(m+y)+r \omega_{2} L z-a_{1} a_{2} K L y(m+y)-\omega_{1} a_{2} K L z(m+y)$.

Also solving (11a) \& (11c), we obtain

$g(y, z)=0$,

where

$g(y, z)=K r b_{1} \omega_{1}(m+y)-r\left\{c(m+y)-b_{2} \omega_{2} y\right\}-K a_{1} b_{1} \omega_{1} y(m+y)-K \omega_{1}^{2} b_{1}(m+y) z$.

From (12) we note the following.

When $\mathrm{z} \rightarrow 0$, then $\mathrm{y} \rightarrow \mathrm{y}_{\mathrm{a}}$, where 


$$
y_{a}=\frac{r L\left(s-a_{2} K\right)}{r s-a_{1} a_{2} K L} .
$$

We note that $\mathrm{y}_{\mathrm{a}}>0$, if the inequality (4a) holds.

Also from the equation (12), we have $\frac{d y}{d z}=\frac{A_{1}}{B_{1}}$, where

$$
\begin{aligned}
A_{1} & =\omega_{1} a_{2} K L(m+y)-r \omega_{2} L, \\
\text { and } \quad B_{1} & =r K L\left(a_{2}-\frac{s}{K}\right)+K L(m+2 y)\left(\frac{r s}{K L}-a_{1} a_{2}\right)-K L \omega_{1} a_{2} z .
\end{aligned}
$$

It is clear that $\frac{d y}{d z}>0$, if either

$$
\begin{array}{ll}
\text { i) } & A_{1}>0 \text { and } B_{1}>0, \text { or } \\
\text { ii) } & A_{1}<0 \text { and } B_{1}<0 \quad \text { hold }
\end{array}
$$

Again from (13), we note that when $\mathrm{z} \rightarrow 0$, then $\mathrm{y} \rightarrow \mathrm{y}_{\mathrm{b}}$, where

$$
\begin{aligned}
& y_{b}=\frac{-B_{2}+\sqrt{B_{2}{ }^{2}-4 A_{2} C_{2}}}{2 A_{2}}, \\
& A_{2}=-a_{1} b_{1} \omega_{1} K, \\
& B_{2}=b_{1} \omega_{1}\left(r-a_{1} m\right) K+r b_{2} \omega_{2}-r c=b_{1} \omega_{1}\left(r-a_{1} m\right) K+r\left(b_{2} \omega_{2}-c\right), \\
& C_{2}=m r\left(b_{1} \omega_{1} K-c\right) .
\end{aligned}
$$

Clearly A2 $<0$ and $\mathrm{C}_{2}>0$ if the inequality (10) is satisfied.

We also have $\frac{d y}{d z}=-\frac{\frac{\partial g}{\partial z}}{\frac{\partial g}{\partial y}}$.

We note that $\frac{d y}{d z}<0$, if either

$$
\frac{\partial g}{\partial y}>0 \text { and } \frac{\partial g}{\partial z}>0
$$

(ii) $\frac{\partial g}{\partial y}<0$ and $\frac{\partial g}{\partial z}<0 \quad$ hold.

From the above analysis we note that two isoclines (12) and (13) intersect at a unique $\left(\mathrm{y}_{7}{ }^{*}, \mathrm{z}_{7}{ }^{*}\right)$ if in addition to conditions (4a), (10), (15) and (16), the inequality

holds.

$$
\mathrm{y}_{\mathrm{a}}<\mathrm{y}_{\mathrm{b}}
$$

Knowing the value of $\mathrm{y}_{7}{ }^{*}$ and $\mathrm{z}_{7}{ }^{*}$, the value of $\mathrm{x}_{7}{ }^{*}$ can be calculated from

$$
x_{7}{ }^{*}=\frac{c\left(m+y_{7}^{*}\right)-b_{2} \omega_{2} y_{7}{ }^{*}}{\left(m+y_{7}{ }^{*}\right) b_{1} \omega_{1}}=\frac{c m-\left(b_{2} \omega_{2}-c\right) y_{7}{ }^{*}}{\left(m+y_{7}{ }^{*}\right) b_{1} \omega_{1}} \text {. }
$$

It may be noted that for $\mathrm{x}_{7}{ }^{*}$ to be positive, we must have

$$
c m>\left(b_{2} \omega_{2}-c\right) y_{7}^{*} \text {. }
$$

This completes the existence of $E_{x y z}\left(x_{7}^{*}, y_{7}{ }^{*}, z_{7}{ }^{*}\right)$.

\section{Linear stability analysis}


The characteristic equation for the model (1) is given by $\left|A+B e^{-\lambda \tau}-\lambda I\right|=0$,

where, $A=\left(a_{i j}\right)_{3 \times 3}, a_{11}=r\left(1-\frac{2 x}{K}\right)-a_{1} y-\omega_{1} z, a_{12}=-a_{1} x, a_{13}=-\omega_{1} x$,

$a_{21}=-a_{2} y, a_{22}=s\left(1-\frac{2 y}{L}\right)-a_{2} x-\frac{\omega_{2} z}{m+y}+\frac{\omega_{2} y z}{(m+y)^{2}}, a_{23}=-\frac{\omega_{2} y}{m+y}$

$a_{31}=a_{32}=a_{33}=0$

$B=\left(b_{1 j}\right)_{3 \times 3}, b_{11}=b_{12}=b_{13}=0, b_{21}=b_{22}=b_{23}=0$,

$b_{31}=b_{1} \omega_{1} z e^{-\lambda z}, b_{32}=\frac{m b_{2} \omega z}{(m+y)^{2}} e^{-\lambda \tau}, b_{33}=b_{1} \omega_{1} x+\frac{b_{2} \omega_{2} y}{(m+y)}-c$.

\section{We first consider the case where $\tau=0$ :}

At $E_{0}(0,0,0)$ the characteristic equation becomes $(\lambda-r)(\lambda-s)(\lambda+c)=0$. So, we arrive at a conclusion:

Theorem 3.1. $E_{o}$ is always a saddle node and there can not be total extinction of the system (1) for positive initial conditions $\square$ For $E_{x}(K, 0,0)$ the characteristic equation becomes $(-r-\lambda)\left(s-a_{2} K-\lambda\right)\left(K b_{1} \omega_{1}-c-\lambda\right)=0$,

and for $E_{y}(0, L 0)$, the characteristic equation becomes $\left(r-a_{1} L-\lambda\right)(-s-\lambda)\left(\frac{b_{2} \omega_{2} L}{m+L}-c-\lambda\right)=0$

Observing the sign of eigenvalues we can state the following theorem:

Theorem 3.2 a) $E_{x}$ is a saddle point with locally stable manifold in $x$ directions and with locally unstable manifold in $y-z$ plane if $\mathrm{s}-\mathrm{a}_{2} \mathrm{~K}>0$ and $\mathrm{Kb}_{1} \omega_{1}<\mathrm{c}$ hold, but if $\mathrm{s}-\mathrm{a}_{2} \mathrm{~K}<0$ and $\mathrm{Kb}_{1} \omega_{1}<\mathrm{c}$, then $\mathrm{E}_{\mathrm{xz}}$ does not exist and in that case $\mathrm{E}_{\mathrm{x}}$ is locally asymptotically stable in $\mathrm{x}-\mathrm{y}-\mathrm{z}$ space.

b) If inequalities $\mathrm{r}-\mathrm{a}_{1} \mathrm{~L}>0$ and $L\left(b_{2} \omega_{2}-c\right)>c m$. hold then $\mathrm{E}_{\mathrm{y}}$ is a saddle point with locally stable manifold in $\mathrm{y}-$ direction and with locally unstable manifold in $\mathrm{x}-\mathrm{z}$ plane. But if $\mathrm{r}-\mathrm{a}_{1} \mathrm{~L}<0$ and $\frac{b_{2} \omega_{2} L}{m+L}-c<0$, then $\mathrm{E}_{\mathrm{yz}}$ does not exist and in that case $\mathrm{E}_{\mathrm{y}}$ is locally asymptotically stable in $\mathrm{x}-\mathrm{y}-\mathrm{z}$ space $\square$

For, $\quad E_{x y}\left(\frac{s K\left(r-a_{1} L\right)}{r s-a_{1} a_{2} K L}, \frac{r L\left(s-a_{2} K\right)}{r s-a_{1} a_{2} K L}, 0\right)$, the characteristic equation becomes

$$
\left|\begin{array}{ccc}
\frac{r s\left(L a_{1}-r\right)}{r s-a_{1} a_{2} K L}-\lambda & \frac{-a_{1} s K\left(r-a_{1} L\right)}{r s-a_{1} a_{2} K L} & \frac{-\omega_{1} s K\left(r-a_{1} L\right)}{r s-a_{1} a_{2} K L} \\
\frac{-a_{2} r L\left(s-K a_{2}\right)}{r s-a_{1} a_{2} K L} & \frac{r s\left(K a_{2}-s\right)}{r s-a_{1} a_{2} K L}-\lambda & \frac{-\omega_{1} s K\left(s-K a_{2}\right)}{m\left(r s-a_{1} a_{2} K L\right)+r L\left(s-K a_{2}\right)} \\
0 & 0 & \frac{b_{1} \omega_{1} s K\left(r-a_{1} L\right)}{r s-a_{1} a_{2} K L}+\frac{b_{1} \omega_{1} r L\left(s-K a_{2}\right)}{m\left(r s-a_{1} a_{2} K L\right)+r L\left(s-K a_{2}\right)}-c-\lambda
\end{array}\right|=0
$$

One of the eigenvalue of the system is $\frac{b_{1} \omega_{1} s K\left(r-a_{1} L\right)}{r s-a_{1} a_{2} K L}+\frac{b_{2} \omega_{2} r L\left(s-K a_{2}\right)}{m\left(r s-a_{1} a_{2} K L\right)+r L\left(s-K a_{2}\right)}-c$

and sum and product of other two eigenvalues are $\left(\frac{r s\left(L a_{1}-r\right)}{r s-a_{1} a_{2} K L}+\frac{r s\left(K a_{2}-s\right)}{r s-a_{1} a_{2} K L}\right)$ and

$\frac{r s\left(r-L a_{1}\right)\left(s-K a_{2}\right)}{\left(r s-a_{1} a_{2} K L\right)}$ respectively. Clearly, when the inequality (4a) holds, the sum of other two eignevalues is negative and product is positive. But when the inequality $(4 \mathrm{~b})$ holds then the product of other two eignevalues is negative. Hence we state out the following theorem:

Theorem 3.3. If the inequality (4a) holds then $E_{x y}$ exists and is asymptotically stable in $x-y$ plane but if the inequality (4b) holds then $E_{x y}$ exists and in that case it will be unstable in $x-y$ plane. Moreover, it will be stable in $x-y-z$ space if 
$\frac{b_{1} \omega_{1} s K\left(r-a_{1} L\right)}{r s-a_{1} a_{2} K L}+\frac{b_{2} \omega_{2} r L\left(s-K a_{2}\right)}{m\left(r s-a_{1} a_{2} K L\right)+r L\left(s-K a_{2}\right)}<c \square$

For, $\quad E_{y z}\left(0, y_{5}{ }^{*}, z_{5}{ }^{*}\right), \quad$ where $y_{5}{ }^{*}=\frac{c m}{b_{2} \omega_{2}-c}, \quad z_{5}{ }^{*}=\frac{s\left(1-y_{5}{ }^{*} / L\right)\left(m+y_{5}{ }^{*}\right)}{\omega_{2}}$,

we state out the following theorem:

Theorem 3.4 $\quad \mathrm{E}_{\mathrm{yz}} \quad$ exists and is asymptotically stable in $\mathrm{y}-\mathrm{z}$ plane if the inequality

$$
c m<L\left(b_{2} \omega_{2}-c\right)<m c+m b_{2} \omega_{2}
$$

holds. Also if the inequality $\mathrm{r}-\mathrm{a}_{1} \mathrm{y}_{5}{ }^{*}-\omega_{1} \mathrm{z}_{5}{ }^{*}<0$ holds, then it will be asymptotically stable in $\mathrm{x}-\mathrm{y}-\mathrm{z}$ space $\square$

For $E_{x z}\left(x_{6}^{*}, 0, z_{6}^{*}\right)$, where $x_{6}^{*}=\frac{c}{b_{1} \omega_{1}}, z_{6}^{*}=\frac{r}{\omega_{1}}\left(1-\frac{c}{K b_{1} \omega_{1}}\right)$, the characteristic equation becomes

$$
\left|\begin{array}{ccc}
\frac{-r c}{K b_{1} \omega_{1}}-\lambda & -\frac{a_{1} c}{b_{1} \omega_{1}} & -\frac{c}{b_{1}} \\
0 & s-\frac{a_{2} c}{b_{1} \omega_{1}}-\frac{r \omega_{2}}{m \omega_{1}}\left(1-\frac{c}{K b_{1} \omega_{1}}\right)-\lambda & 0 \\
r b_{1}\left(1-\frac{c}{K b_{1} \omega_{1}}\right) & \frac{b_{2} \omega_{2}}{m \omega_{1}}\left(1-\frac{c}{K b_{1} \omega_{1}}\right) & -\lambda
\end{array}\right|=0
$$

So as before we state out the following theorem:

Theorem 3.5 If $\mathrm{E}_{\mathrm{xz}}$ exists, then it is asymptotically stable in $\mathrm{x}-\mathrm{y}-\mathrm{z}$ space if the following inequality holds.

$$
\frac{a_{2} c}{b_{1} \omega_{1}}+\frac{r \omega_{2}}{m \omega_{1}}\left(1-\frac{c}{K b_{1} \omega_{1}}\right)>s
$$

Now, to investigate the local stability of interior equilibrium, we first linearize the system (1) using the following transformations

$$
\mathrm{x}=\mathrm{x}_{7}{ }^{*}+\mathrm{X}, \quad \mathrm{y}=\mathrm{y}_{7}{ }^{*}+\mathrm{Y}, \quad \mathrm{z}=\mathrm{z}_{7}{ }^{*}+\mathrm{Z},
$$

where $\mathrm{X}, \mathrm{Y}, \mathrm{Z}$ is small perturbation about $E_{x y z}\left(x_{7}{ }^{*}, y_{7}{ }^{*}, \mathrm{z}_{7}{ }^{*}\right)$, and then the linear form of (1) is given by

$$
\begin{aligned}
& \dot{X}=\frac{-r}{K} x_{7}{ }^{*} X+x_{7}{ }^{*}\left(-a_{1}\right) Y+x_{7}{ }^{*}\left(-\omega_{1}\right) Z, \\
& \dot{Y}=-a_{2} y_{7}{ }^{*} X-\frac{s}{L} y_{7}{ }^{*} Y+\frac{y_{7}{ }^{*} \omega_{2} z_{7}{ }^{*} Y}{\left(m+y_{7}{ }^{*}\right)^{2}}-\frac{\omega_{2}}{m+y_{7}{ }^{*}} y_{7}{ }^{*} Z, \\
& \dot{Z}=z_{7}{ }^{*}\left(b_{1} \omega_{1}\right) X+\left[\frac{b_{2} \omega_{2} z_{7}{ }^{*}}{m+y_{7}{ }^{*}}-\frac{b_{2} \omega_{2} y_{7}{ }^{*} z_{7}{ }^{*}}{\left(m+y_{7}\right)^{2}}\right] Y .
\end{aligned}
$$

We consider the following positive definite function

$U=\frac{1}{2 x_{7}{ }^{*}} X^{2}+\frac{d_{1}}{2 y_{7}{ }^{*}} Y^{2}+\frac{d_{2}}{2 z_{7}{ }^{*}} Z^{2}$, where $\mathrm{d}_{1}, \mathrm{~d}_{2}$ are positive constants to be chosen later.

Differentiating $\mathrm{U}$ with respect to time $\mathrm{t}$ along the solution of linear model 23(b) it can be seen that $\dot{U}$ is negative definite if we

choose $d_{2}=\frac{1}{b_{1}}, d_{1}=\frac{m b_{2}}{b_{1}\left(m+y_{7}^{*}\right)}$ and $\left(a_{1}+a_{2} d_{1}\right)^{2}-4 \frac{r d_{1}}{K}\left(\frac{s}{L}-\frac{\omega_{2} z_{7}^{*}}{\left(m+y_{7}^{*}\right)^{2}}\right) \leq 0$.

Hence we arrive at a conclusion: 
Theorem 3.6 If $\left(a_{1}+a_{2} d_{1}\right)^{2}-4 \frac{r d_{1}}{K}\left(\frac{s}{L}-\frac{\omega_{2} z_{7}^{*}}{\left(m+y_{7}^{*}\right)^{2}}\right) \leq 0, \quad$ then $\mathrm{E}_{\mathrm{xyz}}\left(\mathrm{x}_{7}{ }^{*}, \mathrm{y}_{7}{ }^{*}, \mathrm{z}_{7}{ }^{*}\right)$ is locally asymptotically stable

\section{Global stability and persistence of the system}

Theorem 4.1 a) If the equilibrium $E_{x y}$ exists and is locally asymptotically stable in the interior of positive quadrant of $x-y$ plane then it will be globally asymptotically stable there.

b) If $\mathrm{E}_{\mathrm{yz}}$ exists and is locally asymptotically stable in y-z plane then it will be globally asymptotically stable in the region $R_{+}^{2}$ of yz plane, where $R_{+}^{2} \equiv\left\{(y, z): y>0, z>0,(m+y)^{2}-\frac{L}{S} \omega_{2} z>0\right\}$.

c) If $E_{x z}$ exists and is locally stable then it will be globally asymptotically stable in the positive quadrant of $\mathrm{x}-\mathrm{z}$ plane $\square$

Proof. For $\mathrm{E}_{\mathrm{xy}}$, let $H(x, y)=\frac{1}{x y}, h_{1}(x, y)=r x\left(1-\frac{x}{K}\right)-a_{1} x y$ and

$$
h_{2}(x, y)=s y\left(1-\frac{y}{L}\right)-a_{2} x y .
$$

Clearly $\mathrm{H}(\mathrm{x}, \mathrm{y})>0$ in the interior of positive quadrant of $\mathrm{x}-\mathrm{y}$ plane. Then we have

$$
\Delta(x, y)=\frac{\partial}{\partial x}\left(h_{1} H\right)+\frac{\partial}{\partial y}\left(h_{2} H\right)=-\frac{r}{y K}-\frac{s}{x L}<0 .
$$

Clearly $\Delta(\mathrm{x}, \mathrm{y})$ does not change sign and is not identically zero in the positive quadrant of $\mathrm{x}-\mathrm{y}$ plane. Therefore, by Bendixson-Dulac criterion there exists no limit cycle in the positive quadrant of $\mathrm{x}-\mathrm{y}$ plane. So, if $\mathrm{E}_{\mathrm{xy}}$ is locally asymptotically stable then it will be globally asymptotically stable in the interior of positive quadrant of $\mathrm{x}-\mathrm{y}$ plane (Hale, 1969).

For $\mathrm{E}_{\mathrm{yz}}$, let $H(y, z)=\frac{1}{y z}, h_{1}^{\prime}(y, z)=\operatorname{sy}\left(1-\frac{y}{L}\right)-\frac{\omega_{2} y z}{m+y}$ and

$h_{2}^{\prime}(y, z)=\frac{b_{2} \omega_{2} y z}{m+y}-c z$.

Clearly $\mathrm{H}(\mathrm{y}, \mathrm{z})>0$ in the interior of the positive quadrant of $y-z$ plane. Then we have

$\Delta(\mathrm{y}, \mathrm{z})=\frac{\partial}{\partial \mathrm{y}}\left(\mathrm{h}_{1}{ }^{\prime} \mathrm{H}\right)+\frac{\partial}{\partial \mathrm{z}}\left(\mathrm{h}_{2}{ }^{\prime} \mathrm{H}\right)=-\frac{\mathrm{s}}{\mathrm{Lz}}+\frac{\omega_{2}}{(\mathrm{~m}+\mathrm{y})^{2}}<0$ when $(m+y)^{2}-\frac{L \omega_{2}}{s} \mathrm{z}>0$.

Hence $\mathrm{E}_{\mathrm{yz}}$ is globally asymptotically stable in the region $R_{+}^{2}$ of $\mathrm{y}-\mathrm{z}$ plane, where

$R_{+}^{2} \equiv\left\{(y, z): y>0, z>0,(m+y)^{2}-\frac{L}{s} \omega_{2} z>0\right\}$.

For $\mathrm{E}_{\mathrm{xz}}$, let $H=\frac{1}{x \mathrm{z}}, h_{1}^{\prime \prime}(x, \mathrm{z})=r x\left(1-\frac{x}{K}\right)-\omega_{1} x \mathrm{z}$ and $\mathrm{h}_{1}{ }^{\prime \prime}(\mathrm{x}, \mathrm{z})=\mathrm{b}_{1} \omega_{1} \mathrm{xz}-\mathrm{c}_{1} \mathrm{z}$.

Clearly $\mathrm{H}(\mathrm{x}, \mathrm{z})>0$ in the interior of the positive quadrant of $\mathrm{x}-\mathrm{z}$ plane. Then we have

$\Delta(\mathrm{x}, \mathrm{z})=\frac{\partial}{\partial \mathrm{x}}\left(\mathrm{h}_{1}{ }^{\prime} \mathrm{H}\right)+\frac{\partial}{\partial \mathrm{z}}\left(\mathrm{h}_{2}{ }^{\prime} \mathrm{H}\right)=-\frac{\mathrm{r}}{\mathrm{zK}}<0$ in the positive quadrant of $\mathrm{x}-\mathrm{z}$ plane. Hence $\mathrm{E}_{\mathrm{xz}}$ is globally asymptotically stable in the positive quadrant of $\mathrm{x}-\mathrm{z}$ plane $\square$

Theorem 4.2 Let the following hold

$$
\left(a_{1}+d_{1} a_{2}\right)^{2} \leq 4 \frac{r}{K}\left(\frac{d_{1} s}{L}-\frac{d_{1} \omega_{2} z_{7}^{*}}{(m+y)\left(m+y_{7}^{*}\right)}\right),
$$


where $d_{1}, d_{2}$ are same as defined in 23(c), then the positive equilibrium $E_{x y z}$ is globally asymptotically stable with respect to all solutions initiating in the interior of $R_{+}^{3}$

Proof. Consider the following positive definite function about $E_{x y z}\left(x_{7}{ }^{*}, y_{7}{ }^{*}, z_{7}{ }^{*}\right)$.

$$
V=\left(x-x_{7}^{*}-x_{7}^{*} \ln \left(\frac{x}{x_{7}^{*}}\right)\right)+d_{1}\left(y-y_{7}^{*}-y_{7}^{*} \ln \left(\frac{y}{y_{7}^{*}}\right)\right)+d_{2}\left(z-z_{7}^{*}-z_{7}^{*} \ln \left(\frac{z}{z_{7}^{*}}\right)\right) \text {. }
$$

Differentiating $\mathrm{V}$ with respect to $t$ along the solution of model (1), we get

$$
\dot{V}=\left(x-x_{7}^{*}\right) \frac{\dot{x}}{x}+d_{1}\left(y-y_{7}^{*}\right) \frac{\dot{y}}{y}+d_{2}\left(z-z_{7}^{*}\right) \frac{\dot{z}}{z} .
$$

Using the system of equation (1), we get

$$
\begin{gathered}
\dot{V}=-\frac{r}{K}\left(x-x_{7}^{*}\right)^{2}-d_{1} \frac{s}{L}\left(y-y_{7}^{*}\right)^{2}-\left(a_{1}+d_{1} a_{2}\right)\left(x-x_{7}^{*}\right)\left(y-y_{7}^{*}\right) \\
-\left(\omega_{1}-b_{1} \omega_{1} d_{2}\right)\left(x-x_{7}^{*}\right)\left(z-z_{7}^{*}\right)-\frac{m \omega_{2}\left(d_{1}-d_{2} b_{2}\right)}{(m+y)\left(m+y_{7}^{*}\right)}\left(y-y_{7}^{*}\right)\left(z-z_{7}^{*}\right) \\
-\frac{d_{1} \omega_{2} y_{7}^{*}}{(m+y)\left(m+y_{7}^{*}\right)}\left(y-y_{7}^{*}\right)\left(z-z_{7}^{*}\right)+\frac{d_{1} \omega_{2} z_{7}^{*}}{(m+y)\left(m+y_{7}^{*}\right)}\left(y-y_{7}^{*}\right)^{2} .
\end{gathered}
$$

The above equation can further be written as

$$
\begin{array}{r}
\dot{V}=-\left[b_{11}\left(x-x_{7}^{*}\right)^{2}+b_{12}\left(x-x_{7}^{*}\right)\left(y-y_{7}^{*}\right)+b_{22}\left(y-y_{7}^{*}\right)^{2}\right] \\
+b_{13}\left(x-x_{7}^{*}\right)\left(z-z_{7}^{*}\right)+b_{23}\left(y-y_{7}^{*}\right)\left(z-z_{7}^{*}\right),
\end{array}
$$

where, $\quad b_{11}=\frac{r}{K}, b_{12}=\left(a_{1}+d_{1} a_{2}\right), b_{13}=-\omega_{1}\left(1-b_{1} d_{2}\right)$

$b_{22}=\frac{d_{1} s}{L}-\frac{d_{1} \omega_{2} z_{7}^{*}}{(m+y)\left(m+y_{7}^{*}\right)}, b_{23}=\frac{m \omega_{2}\left(d_{2} b_{2}-d_{1}\right)-d_{1} \omega_{2} y_{7}^{*}}{(m+y)\left(m+y_{7}\right)^{*}}$

Let us choose $d_{2}=\frac{1}{b_{1}}$, and $d_{1}=\frac{m b_{2}}{b_{1}\left(m+y_{7}^{*}\right)}$, then the sufficient condition for $\dot{\mathrm{V}}$ to be negative definite is $\quad b_{11}>0$, and

$$
b_{12}{ }^{2}-4 b_{11} b_{22} \leq 0 \text {. }
$$

We note that $b_{11}>0$ always. Also (24) $\Rightarrow(25)$,

Hence $V$ is a Lipunov function with respect to $E_{x y z}$.

To examine the permanence of the system (1) we shall use the method of "average lyapunov function"

( Gard and Hallam, 1997; Hafbauer, 1981). This method was first applied by Hutson and Vickers (1983) to ecological problems.

Let the average Liapunov function for the system (1) be $\sigma(X)=x^{p} y^{p_{1}} z^{p_{2}}$, where $p, p_{1}$ and $p_{2}$ are positive constants. Clearly in the interior of $\mathrm{R}_{+}^{3}$ we have

$$
\begin{aligned}
\Psi(X)=\frac{\dot{\sigma}(X)}{\sigma(X)}= & p \frac{\dot{x}}{x}+p_{1} \frac{\dot{y}}{y}+p_{2} \frac{\dot{z}}{z} \\
= & p\left[r\left(1-\frac{x}{K}\right)-a_{1} y-\omega_{1} z\right]+p_{1}\left[s\left(1-\frac{y}{L}\right)-a_{2} x-\frac{\omega_{2} z}{m+y}\right] \\
& +p_{2}\left[b_{1} \omega_{1} x+\frac{b_{2} \omega_{2} y}{m+y}-c\right] .
\end{aligned}
$$

Let us assume that inequalities (4a), (7) and (10) hold. Also the hypothesis of theorem 4.1 holds. 
Then $\mathrm{E}_{\mathrm{xy}}, \mathrm{E}_{\mathrm{yz}}$ and $\mathrm{E}_{\mathrm{zx}}$ exist, further there are no periodic orbits in the interior of $\mathrm{x}-\mathrm{y}$ plane, $\mathrm{x}-\mathrm{z}$ plane and in the region $\mathrm{R}_{+}{ }^{2}$ of $\mathrm{y}$ - z plane.

Thus to prove the uniform persistence of the system, it is enough to show that $\psi(X)>0$ in the domain $\mathrm{D}$ of $\mathrm{R}_{+}{ }^{3}$ where

$$
D \equiv\left\{(x, y, z): x>0, y>0, z>0,(m+y)^{2}-\frac{L \omega_{2}}{s} z>0\right\}
$$

for a suitable choice of $\mathrm{p}, \mathrm{p}_{1}$ and $\mathrm{p}_{2}>0$.

That is one that has to satisfy the following conditions.

$$
\begin{aligned}
& \Psi\left(E_{o}\right)=p r+p_{1} s-p_{2} c>0, \\
& \Psi\left(E_{x}\right)=p_{1} s-p_{1} a_{2} K+p_{2} b_{1} \omega_{1} K-p_{2} c=p_{1}\left(s-a_{2} K\right)+p_{2}\left(b_{1} \omega_{1} K-c\right)>0, \\
& \Psi\left(E_{y}\right)=p r-p a_{1} L+p_{2}\left(\frac{b_{2} \omega_{2} L}{m+L}-c\right)=p\left(r-a_{1} L\right)+p_{2}\left(\frac{b_{2} \omega_{2} L}{m+L}-c\right)>0, \\
& \Psi\left(E_{x y}\right)=p_{2}\left[\frac{b_{1} \omega_{1} s K\left(r-a_{1} L\right)}{r s-a_{1} a_{2} K L}+\frac{b_{2} \omega_{2} r L\left(s-K a_{2}\right)}{m\left(r s-a_{1} a_{2} K L\right)-r L\left(s-K a_{2}\right)}-c\right]>0, \\
& \Psi\left(E_{y z}\right)=p\left[r-\left\{\frac{a_{1} c m}{b_{2} \omega_{2}-c}+\frac{\omega_{1} s}{\omega_{2}}\left(1-\frac{c m}{L\left(b_{2} \omega_{2}-c\right)}\right)\left(m+\frac{c m}{b_{2} \omega_{2}-c}\right)\right\}\right]>0, \\
& \Psi\left(E_{x z}\right)=p_{1}\left[s-\frac{a_{2} c}{b_{1} \omega_{1}}-\frac{\omega_{2} r}{m \omega_{1}}\left(1-\frac{c}{K b_{1} \omega_{1}}\right)\right]>0 .
\end{aligned}
$$

We note that by increasing $\mathrm{p}$ to sufficiently large value, $\psi\left(\mathrm{E}_{\mathrm{o}}\right)$ can be made positive. Thus inequality $26(\mathrm{a})$ holds. Inequalities (4a) $\&$ (10) imply that 26(b) holds. So we state out the following theorem.

Theorem 4. 3 In addition to inequalities (4a) and (10) let the hypotheses of theorem 4.1 hold, and then the system (1) is uniformly persistent if the following inequalities hold

$$
\begin{aligned}
& \frac{b_{1} \omega_{1} s K\left(r-a_{1} L\right)}{r s-a_{1} a_{2} K L}+\frac{b_{2} \omega_{2} r L\left(s-K a_{2}\right)}{m\left(r s-a_{1} a_{2} K L\right)-r L\left(s-K a_{2}\right)}>c, \\
& r>\frac{a_{1} c m}{b_{2} \omega_{2}-c}+s \frac{\omega_{1}}{\omega_{2}}\left(1-\frac{c m}{L\left(b_{2} \omega_{2}-c\right)}\right)\left(m+\frac{c m}{b_{2} \omega_{2}-c}\right), \\
& s-\frac{a_{2} c}{b_{1} \omega_{1}}-\frac{\omega_{2}}{m \omega_{1}} r\left(1-\frac{c}{K b_{1} \omega_{1}}\right)>0
\end{aligned}
$$

Theorem 4. 4. If 23(c) holds, then the equilibrium $E_{x y z}$ is asymptotically stable for $\tau<\tau_{\mathrm{o}}$ and unstable for $\tau>\tau_{0}$. Further, as $\tau$ increases through $\tau_{\mathrm{o}}, \mathrm{E}_{\mathrm{xyz}}\left(\mathrm{x}_{7}{ }^{*}, \mathrm{y}_{7}{ }^{*}, \mathrm{z}_{7}{ }^{*}\right)$ bifurcates into small amplitude periodic solutions, where $\tau_{\mathrm{o}}=\tau_{\mathrm{on}}$ as $\mathrm{n}=0 \square$.

Proof. The characteristic equation for the case where $\tau \neq 0$ is given by

$\lambda^{3}+\lambda^{2}(\mathrm{~A}+\mathrm{B})+\lambda(\mathrm{AB}-\mathrm{C})+\mathrm{e}^{-\lambda \tau}\{\lambda(\mathrm{D}+\mathrm{E})+\mathrm{AD}+\mathrm{BE}-\mathrm{F}\}=0$

where $\mathrm{A}=(\mathrm{r} / \mathrm{K}) \mathrm{x}_{7}^{*}, \mathrm{~B}=(\mathrm{s} / L) y_{7}^{*}-\left(\omega_{2} y_{7}^{*} \mathrm{z}_{7}^{*}\right) /\left(m+y_{7}^{*}\right)^{2}, C=a_{1} a_{2} x_{7}^{*} y_{7}^{*}$,

$D=\left(m b_{2} \omega_{2}^{2} y_{7}^{*} z_{7}^{*}\right) /\left(m+y_{7}^{*}\right)^{3}, E=b_{1} \omega_{1}^{2} x_{7}^{*} z_{7}^{*}, F=\left(\omega_{1} \omega_{2} x_{7}^{*} y_{7}^{*} z_{7}^{*}\right)\left\{m\left(a_{1} b_{1}+a_{2} b_{2}\right)+a_{1} b_{1} y_{7}^{*}\right\} /\left(m+y_{7}^{*}\right)^{2}$.

Now $\lambda=i \omega(\omega>0)$ in $28(a)$ gives

$-i \omega^{3}-\omega^{2}(A+B)+i \omega(A B-C)+(\cos \omega \tau-i \sin \omega \tau)\{i \omega(D+E)+A D+B E-F\}=0$.

Comparing real and imaginary parts we get,

$-\omega^{3}+\omega(\mathrm{AB}-\mathrm{C})=(\mathrm{AD}+\mathrm{BE}-\mathrm{F}) \sin \omega \tau-(\mathrm{D}+\mathrm{E}) \omega \cos \omega \tau$,

$-\omega^{2}(\mathrm{~A}+\mathrm{B})=-(\mathrm{D}+\mathrm{E}) \omega \sin \omega \tau-(\mathrm{AD}+\mathrm{BE}-\mathrm{F}) \cos \omega \tau$.

Squaring and adding $28(\mathrm{~b})$ and $28(\mathrm{c})$ we get, $\omega^{6}+\mathrm{Q}_{1} \omega^{4}+\mathrm{Q}_{2} \omega^{2}+\mathrm{Q}_{3}=0$,

where, $Q_{1}=\left(A^{2}+B^{2}+2 C\right), Q_{2}=\left\{(A B-C)^{2}-(D+E)^{2}\right\}, Q_{3}=-(A D+B E-F)^{2}$. 
So equation 28(d) has unique positive solution $\omega_{\mathrm{o}}{ }^{2}$ irrespective of the sign of $Q_{2}$, as $Q_{1}>0$

and $Q_{3}<0$. Now, from 28 (b) and 28 (c) we get,

$\cos \omega \tau=\frac{(D+E) \omega^{4}+\omega^{2}\{(A+B)(A D+B E-F)-(A B-C)(D+E)\}}{(D+E)^{2} \omega^{2}+(A D+B E-F)^{2}}$.

So, corresponding to $\lambda=i \omega_{0}$, there exists $\tau_{0 \mathrm{n}}$ such that,

$\tau_{0 n}=\frac{1}{\omega_{0}} \arccos \left[\frac{(D+E) \omega^{4}+\omega^{2}\{(A+B)(A D+B E-F)-(A B-C)(D+E)}{(D+E)^{2} \omega^{2}+(A D+B E-F)^{2}}\right]+\frac{2 n \pi}{\omega_{0}}$.

$\mathrm{n}=0,1,2, \ldots$

Now differentiation of 28(a) with respect to $\tau$ gives,

$\begin{aligned} & \left(\frac{d \lambda}{d \tau}\right)^{-1}=\frac{3 \lambda^{2}+2 \lambda(A+B)+(A B-C)}{\lambda e^{-\lambda \tau}\{\lambda(D+E)+A D+B E-F\}}+\frac{D+E}{\lambda\{\lambda(D+E)+A D+B E-F\}}-\frac{\tau}{\lambda} \\ = & \frac{3 \lambda^{3}+2 \lambda^{2}(A+B)+\lambda(A B-C)}{\lambda^{2} e^{-\lambda \tau}\{\lambda(D+E)+A D+B E-F\}}+\frac{D+E}{\lambda\{\lambda(D+E)+A D+B E-F\}}-\frac{\tau}{\lambda} \\ = & \frac{2 \lambda^{3}+\lambda^{2}(A+B)-e^{-\lambda \tau}\{\lambda(D+E)+A D+B E-F\}}{\lambda^{2} e^{-\lambda \tau}\{\lambda(D+E)+A D+B E-F\}}+\frac{D+E}{\lambda\{\lambda(D+E)+A D+B E-F\}}-\frac{\tau}{\lambda} \\ = & \frac{2 \lambda^{3}+\lambda^{2}(A+B)}{-\lambda^{2}\left\{\lambda^{3}+\lambda^{2}(A+B)+\lambda(A B-C)\right\}}+\frac{D+E}{\lambda\{\lambda(D+E)+A D+B E-F\}}-\frac{1}{\lambda^{2}}-\frac{\tau}{\lambda} \\ = & \frac{2 \lambda^{2}+\lambda(A+B)}{-\lambda^{2}\left\{\lambda^{2}+\lambda(A+B)+(A B-C)\right\}}-\frac{A D+B E-F}{\lambda^{2}\{\lambda(D+E)+A D+B E-F\}}-\frac{\tau}{\lambda} \\ \therefore & \left(\frac{d \lambda}{d \tau}\right)_{\lambda=i \omega_{0}}^{-1}=\frac{-2 \omega_{0}+i(A+B)}{\omega_{0}\left\{-\omega_{0}^{2}+i \omega_{0}(A+B)+(A B-C)\right\}}+\frac{A D+B E-F}{\omega_{0}^{2}\left\{(A D+B E-F)+i \omega_{0}(D+E)\right\}}-\frac{\tau}{i \omega_{0}} \\ = & \frac{\left\{-2 \omega_{0}+i(A+B)\right\}\left\{A B-C-\omega_{0}^{2}-i \omega_{0}(A+B)\right\}}{\omega_{0}\left\{\left(A B-C-\omega_{0}^{2}\right)^{2}+\omega_{0}^{2}(A+B)^{2}\right\}}+\frac{(A D+B E-F)\left\{(A D+B E-F)-i \omega_{0}(D+E)\right\}}{\omega_{0}^{2}\left\{(A D+B E-F)^{2}+(D+E)^{2} \omega_{0}^{2}\right\}}+\frac{i \tau}{\omega_{0}} . \\ & \operatorname{Re}\left\{\left(\frac{d \lambda}{d \tau}\right)_{\tau=i \omega_{0}}^{-1}\right\}=\left[\frac{\left(A^{2}+B^{2}+2 C\right)+2 \omega_{0}^{2}}{\left(A B-C-\omega_{0}^{2}\right)^{2}+\omega_{0}^{2}(A+B)^{2}}\right]+\left[\frac{(A D+B E-F)^{2}}{\omega_{0}^{2}\left\{(A D+B E-F)^{2}+(D+E)^{2} \omega_{0}^{2}\right\}}\right]>\quad \text { Therefore the }\end{aligned}$

transversability condition holds and hence Hopf-bifurcation occurs at $\tau=\tau_{0}$. This completes the proof.

\section{Simulation and discussion}

In this paper we studied the dynamical behaviors of a two prey one predator system. . Holling type I response function is taken to represent the interaction between one of the prey and predator. The interaction between the other prey and the predator is assumed to be governed by a Holling type II response function. Such different choices of functional responses may be particularly useful when handling time for one prey is negligible, whereas the predator needs sufficient handling time for other prey. A good example of a two prey one predator system is minke whale (predator) and two of its main prey juvenile herring and capelin.

To illustrate the results numerically, choose $\mathrm{r}=3.5, \mathrm{~K}=150, \mathrm{a}_{1}=0.001, \mathrm{w}_{1}=0.24, \mathrm{~s}=4.5, \mathrm{~L}=150, \mathrm{a}_{2}=0.1, \mathrm{w}_{2}=0.21, \mathrm{~m}=15, \mathrm{~b}_{1}=0.5$, $\mathrm{b}_{2}=0.6, \mathrm{c}=3.9$ in appropriate units.

With the above parameter values, system (1) has a positive equilibrium $(31.72,42.89,11.32)$, which is globally asymptotically stable (see Figs. 1, 2). 


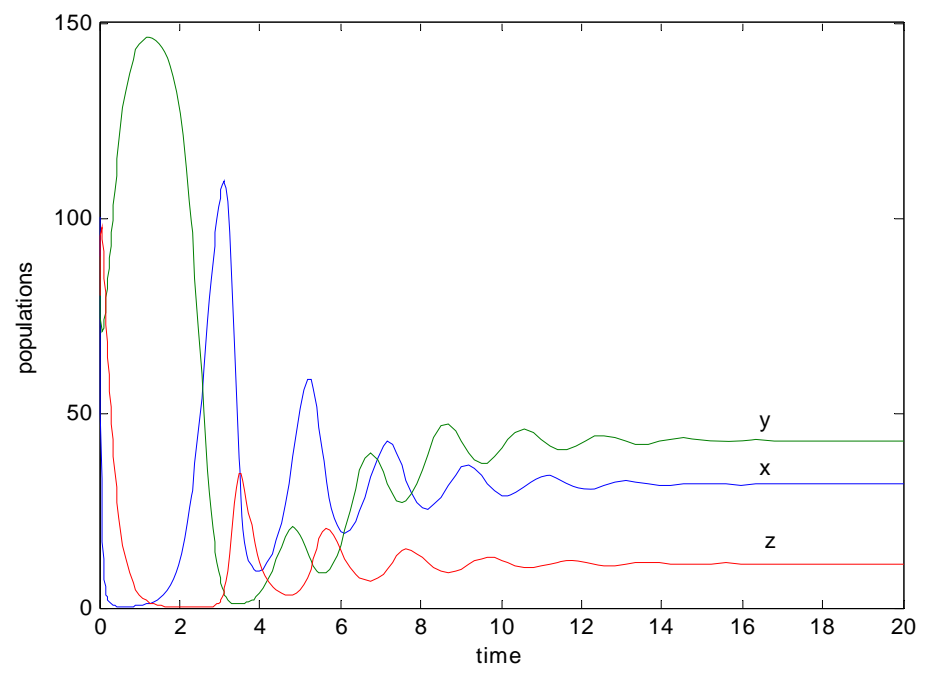

Fig.1. Time evolution of all the population for the model system (1). Population converges to the positive equilibrium $(31.72,42.89,11.32)$.

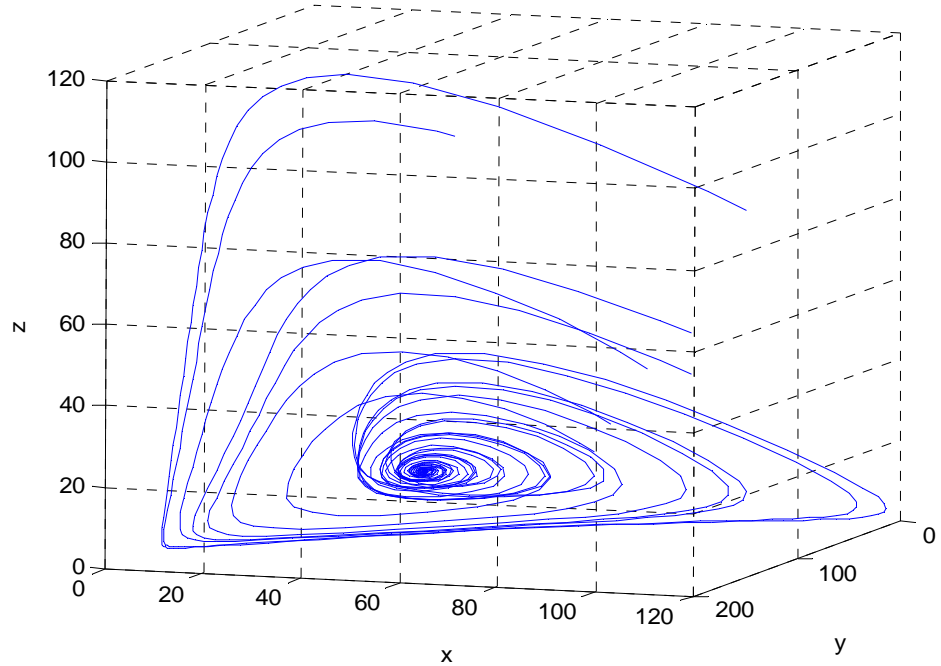

Fig.2. Phase portrait of the system (1), corresponding to different initial levels. The figure clearly indicates that the interior equilibrium point $(31.72,42.89,11.32)$ is globally asymptotically stable.

Often we come across several biological systems in nature exhibiting cycle behavior. Due to this cyclic nature some population exhibit periodic fluctuation in abundance, with periodic crashes. One could avoid such crashes and stabilize the population by controlling one of the interacting species. (Hudson et al., 1998). Thus it is relevant to find conditions under which a multispecies system exhibits cyclic behavior and it is equally important to find conditions under which cycles can be prevented in a multispecies system.

By using Liu's criterion (see appendix) It is interesting to observe that, when the inter-species interference co-efficient $\mathrm{a}_{1}$ of two prey species is increased, the positive equilibrium losses its stability and a Hopf- bifurcation occurs when $\mathrm{a}_{1}$ passes a critical value.

With parameter values $\mathrm{r}=3.5, \mathrm{~K}=150, \mathrm{w}_{1}=0.24, \mathrm{~s}=4.5, \mathrm{~L}=150, \mathrm{a}_{2}=0.2731614, \mathrm{w}_{2}=0.21, \mathrm{~m}=15, \mathrm{~b}_{1}=0.5, \mathrm{~b}_{2}=0.6, \mathrm{c}=1.7$ in appropriate units, a super critical Hopf bifurcation occurs when $a_{1}{ }^{*}=0.01981331$. Now, if we gradually increase the value of $a_{1}$, keeping other parameters fixed, then $\mathrm{E}_{\mathrm{xyz}}$ losses its stability as $\mathrm{a}_{1}$ crosses its critical value $\mathrm{a}_{1}{ }^{*}=0.01981331$ (see Figs 2-4). 


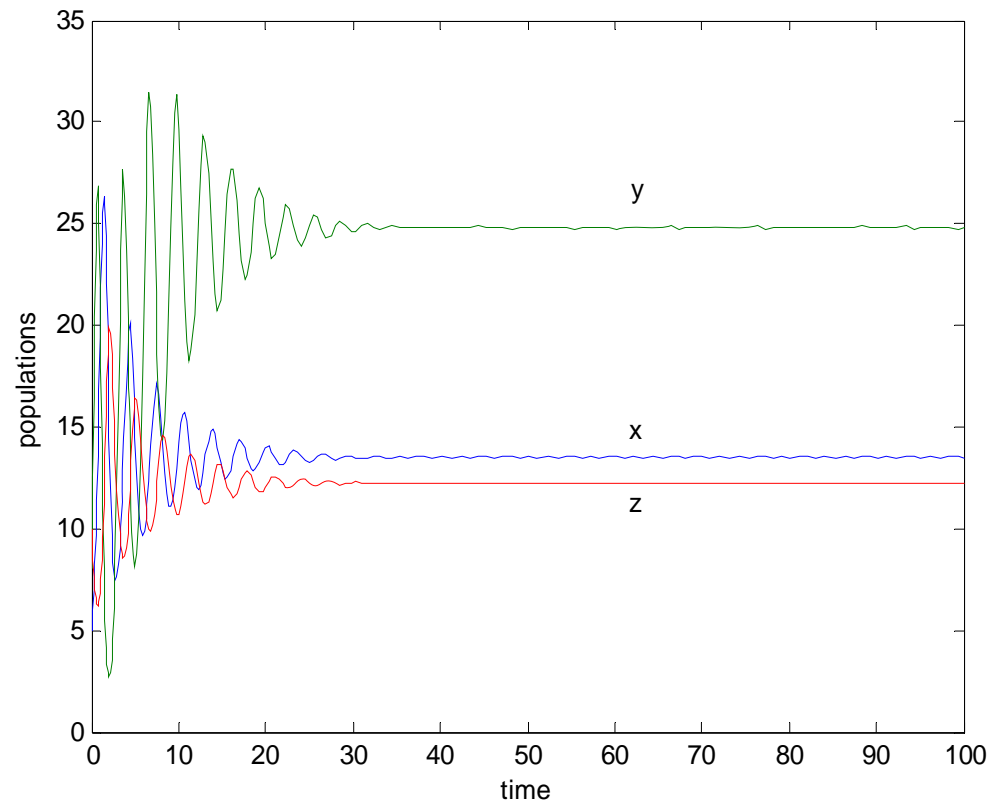

Fig. 3. When $\mathrm{a}_{1}=0.01<\mathrm{a}_{1}$, clearly the populations approach their equilibrium values in finite time. Here parameter values are $\mathrm{r}=3.5, \mathrm{~K}=150, \mathrm{w}_{1}=0.24, \mathrm{~s}=4.5, \mathrm{~L}=150, \mathrm{a}_{2}=0.273164, \mathrm{w}_{2}=0.21, \mathrm{~m}=15, \mathrm{~b}_{1}=0.5, \mathrm{~b}_{2}=0.6, \mathrm{c}=1.7$ in appropriate units.

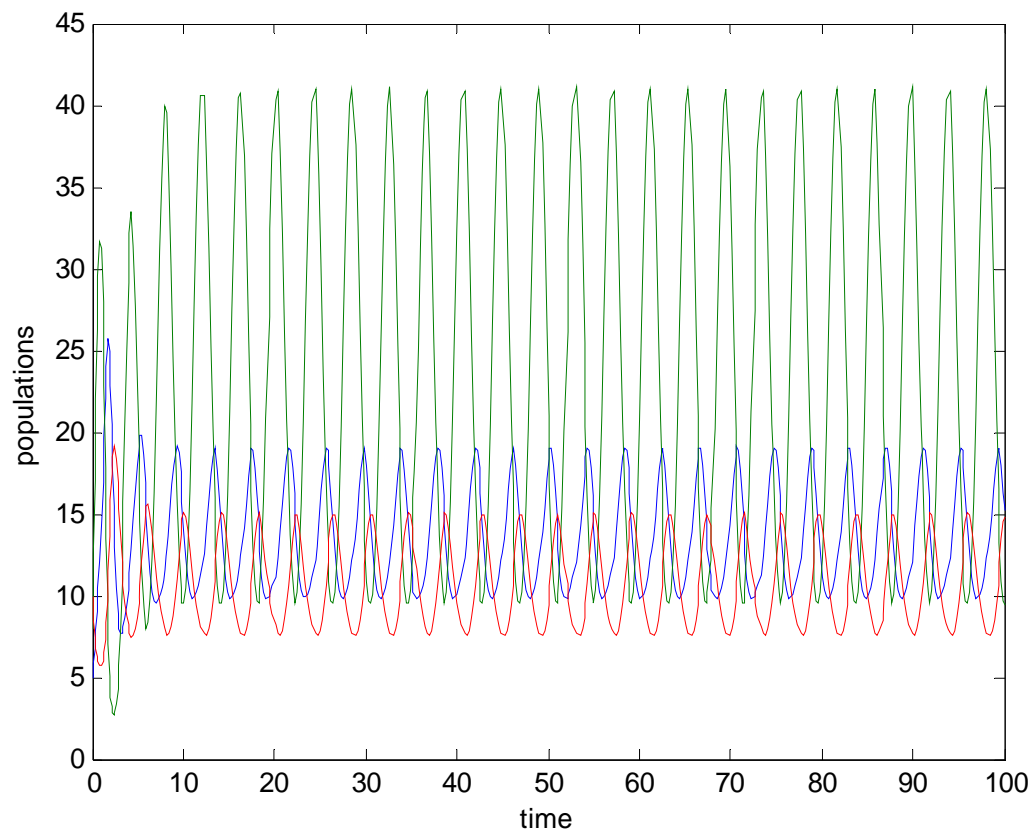

Fig.4. Unstable solution of system (1). Here all the parameters are same as in Fig.3. except $a_{1}=0.025>a_{1} *$. 


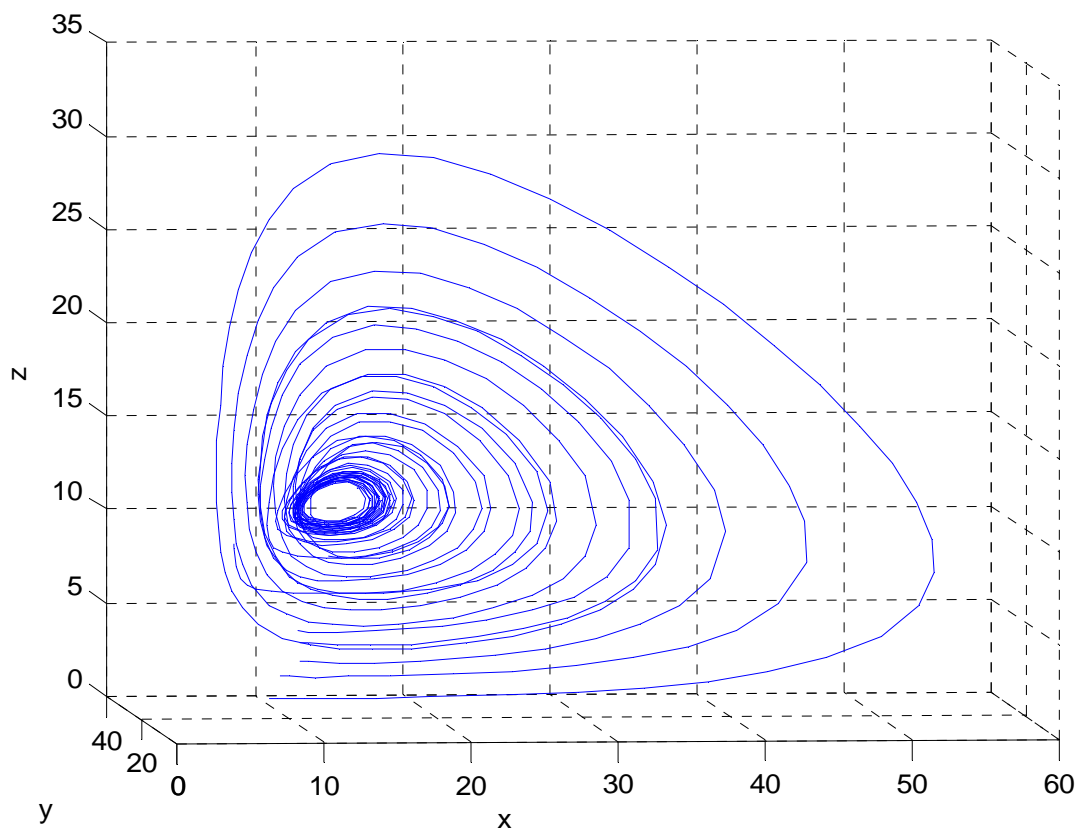

Fig.5. For $\mathrm{a}_{1}=\mathrm{a}_{1} *$, there is a limit cycle near $\mathrm{E}_{\mathrm{xyz}}$.

Also as before we can consider $\mathrm{c}$ (the mortality rate co-efficient of the predator) as the bifurcation parameter. With parameter values $\mathrm{r}=3.5, \mathrm{~K}=150, \mathrm{w}_{1}=0.24, \mathrm{~s}=4.5, \mathrm{~L}=150, \mathrm{a}_{1}=0.015, \mathrm{a}_{2}=0.27, \mathrm{w}_{2}=0.21, \mathrm{~m}=9.0, \mathrm{~b}_{1}=0.5, \mathrm{~b}_{2}=0.6$ in appropriate units, a supercritical Hopf bifurcation occurs when $\mathrm{c}^{*}=1.674233$.

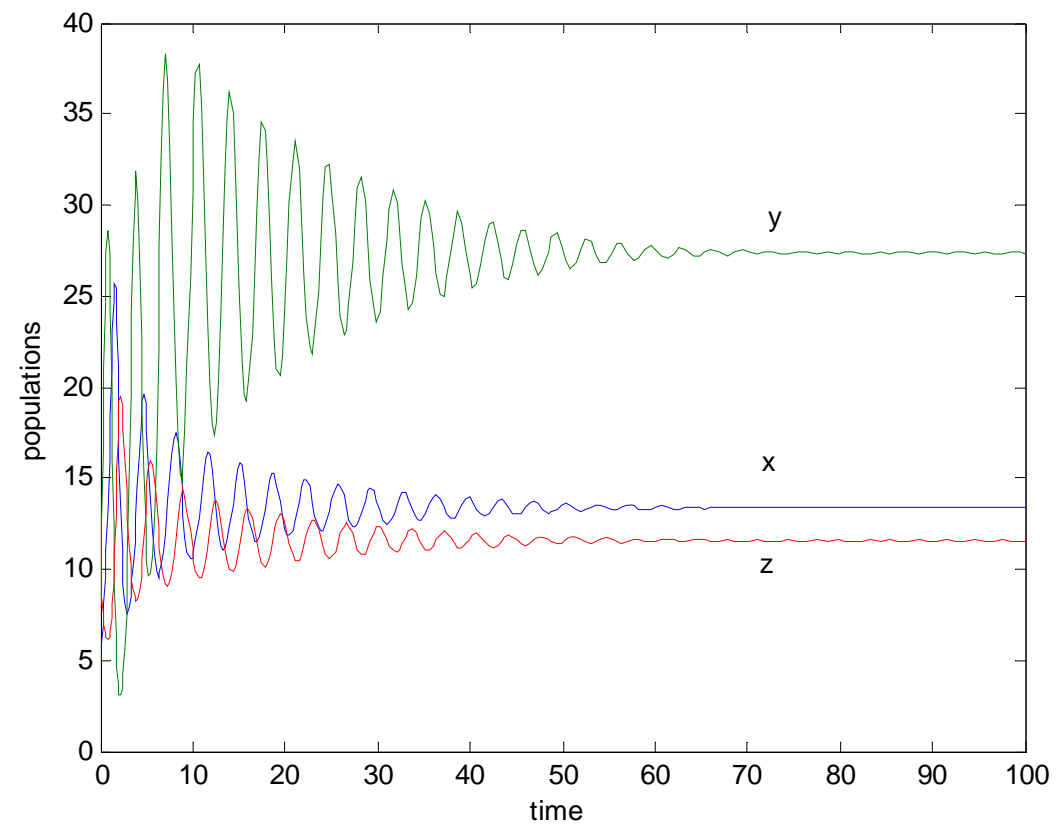

Fig.6. When $c=1.7>c^{*}$, clearly the populations approach their equilibrium values in finite time . Here parameters values are $\mathrm{r}=3.5, \mathrm{~K}=150, \mathrm{w}_{1}=0.24, \mathrm{~s}=4.5, \mathrm{~L}=150, \mathrm{a}_{1}=0.015, \mathrm{a}_{2}=0.27, \mathrm{w}_{2}=0.21, \mathrm{~m}=9.0, \mathrm{~b}_{1}=0.5$, $\mathrm{b}_{2}=0.6$ in appropriate units. 


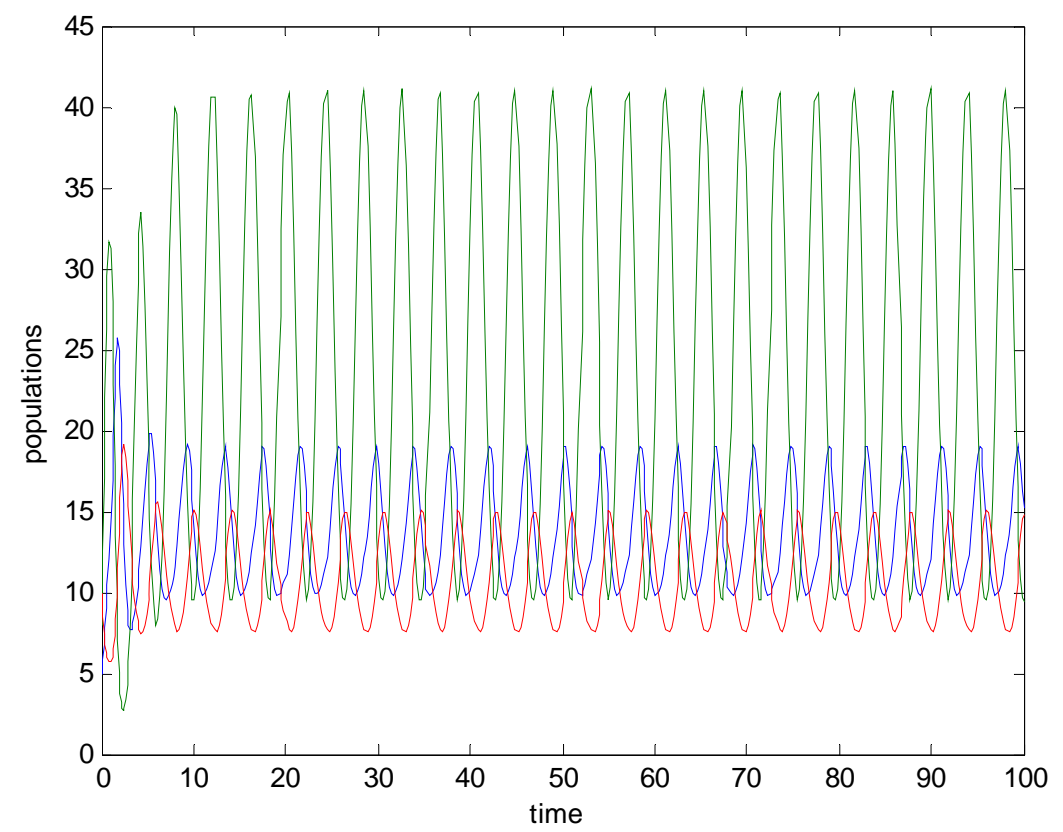

Fig.7. Unstable solutions of system (10). Here all the parameters are same as Fig.6. except $\mathrm{c}=1.5<\mathrm{c}^{*}$.

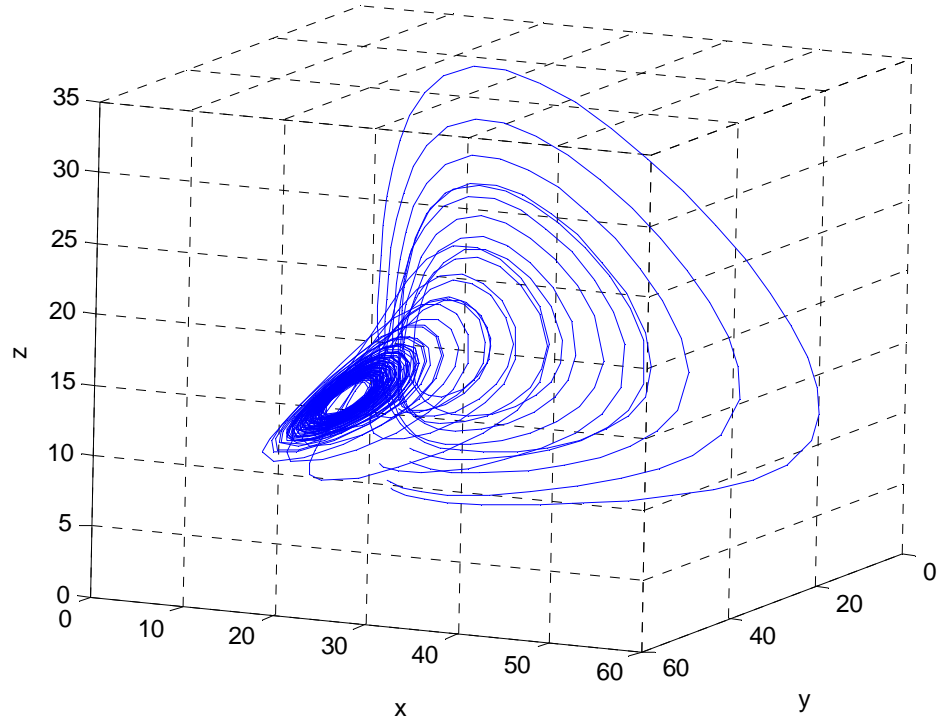

Fig.8. For $\mathrm{c}=\mathrm{c}^{*}$ there is a limit cycle near $\mathrm{E}_{\mathrm{xyz}}$.

The numerical study presented here shows that, using parameter $\mathrm{a}_{1}$ or $\mathrm{c}$ as control, it is possible to break unstable behaviour of the system (1) and drive it to a stable state. In the similar fashion we can consider $\mathrm{a}_{2}$ as a control parameter. Also it is possible to keep the population levels at a required state using the above control. So, we see that in our model dynamics competition plays an important role.

Our results established criteria which guarantee the persistence of the three species and the global dynamics of the model system. It has long been recognized that most of the studies of continuous time deterministic models reveal two basic patterns: approach to an equilibrium or to a limit cycle. The basic rationale behind such type of analysis was the implicit assumption that most food chains we observe in nature correspond to stable equilibria of the model. From this viewpoint, we presented the stability and bifurcation of the most important equilibrium point $\mathrm{E}_{\mathrm{xyz}}$. We see that $\mathrm{E}_{\mathrm{xyz}}\left(\mathrm{x}_{7}{ }^{*}, \mathrm{y}_{7}{ }^{*}, \mathrm{z}_{7}{ }^{*}\right)$ is locally asymptotically stable in the absence of delay. Now for the same values of parameters as for the first figure, it is seen from the Theorem 4.4, that there exists a critical value of $\tau=\tau_{0}=0.0726532$ and $\mathrm{E}_{\mathrm{xyz}}$ losses its stability as $\tau$ crosses the critical value $\tau_{0}$. 
We have also given some graphical representation in favors of our numerical results.

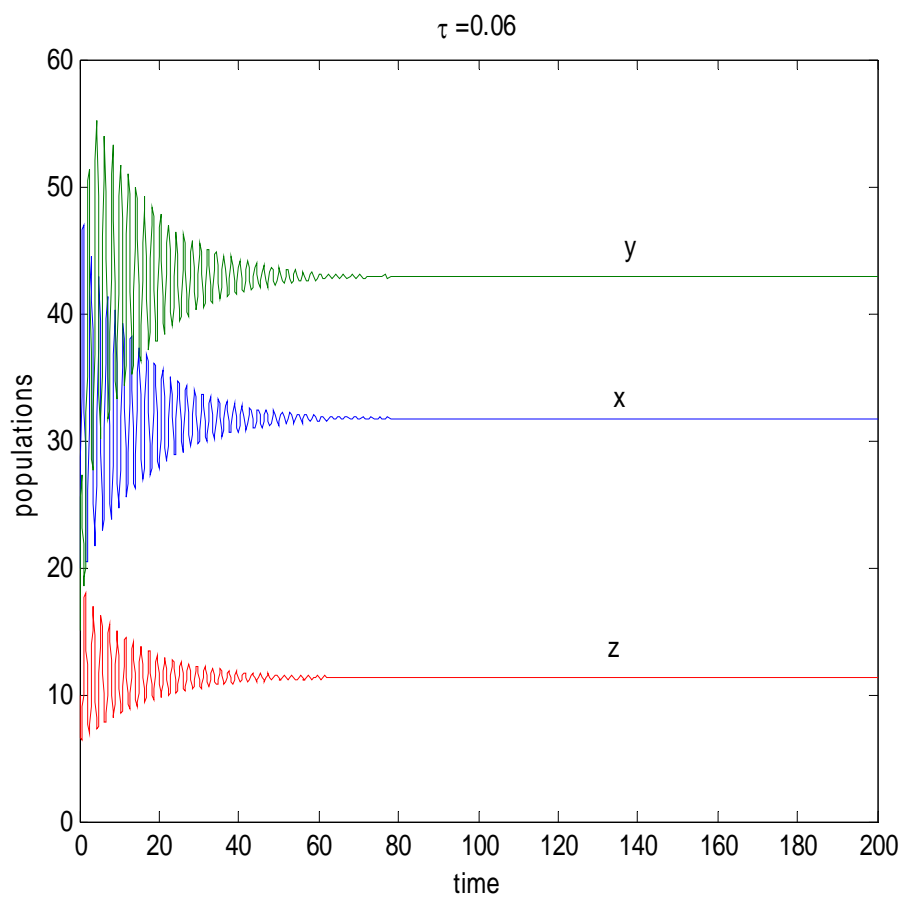

Fig.9. When $\tau=0.06<\tau_{0}$, clearly the populations approach their equilibrium values in finite time.

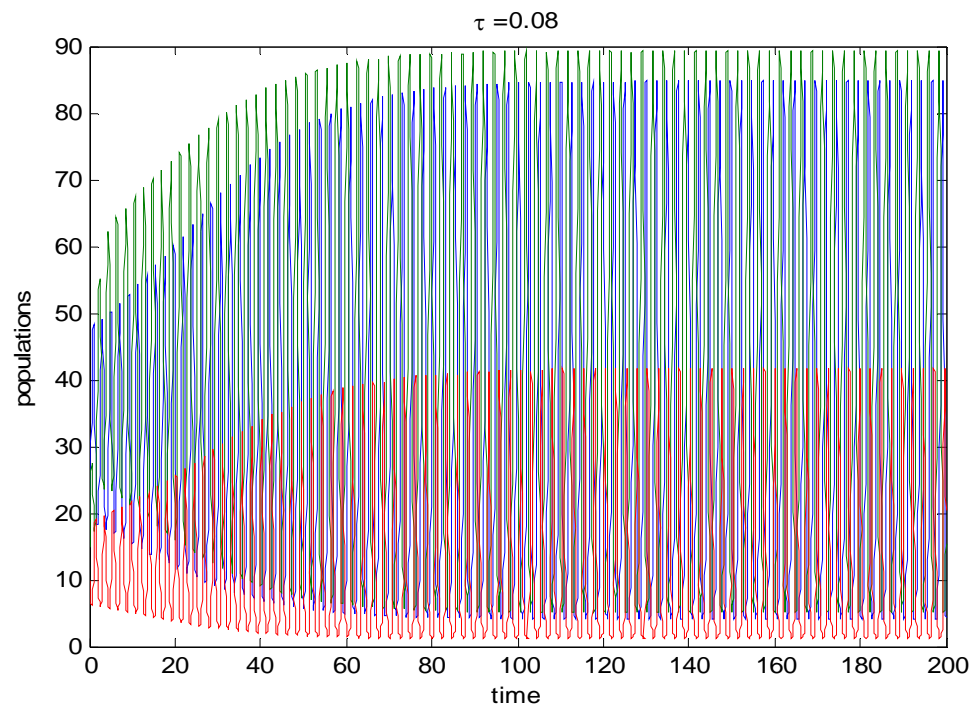

Fig.10. Unstable solution of system (1). Here all the parameters are same as in figure 1, except $\tau=0.08>\tau_{0}$. 


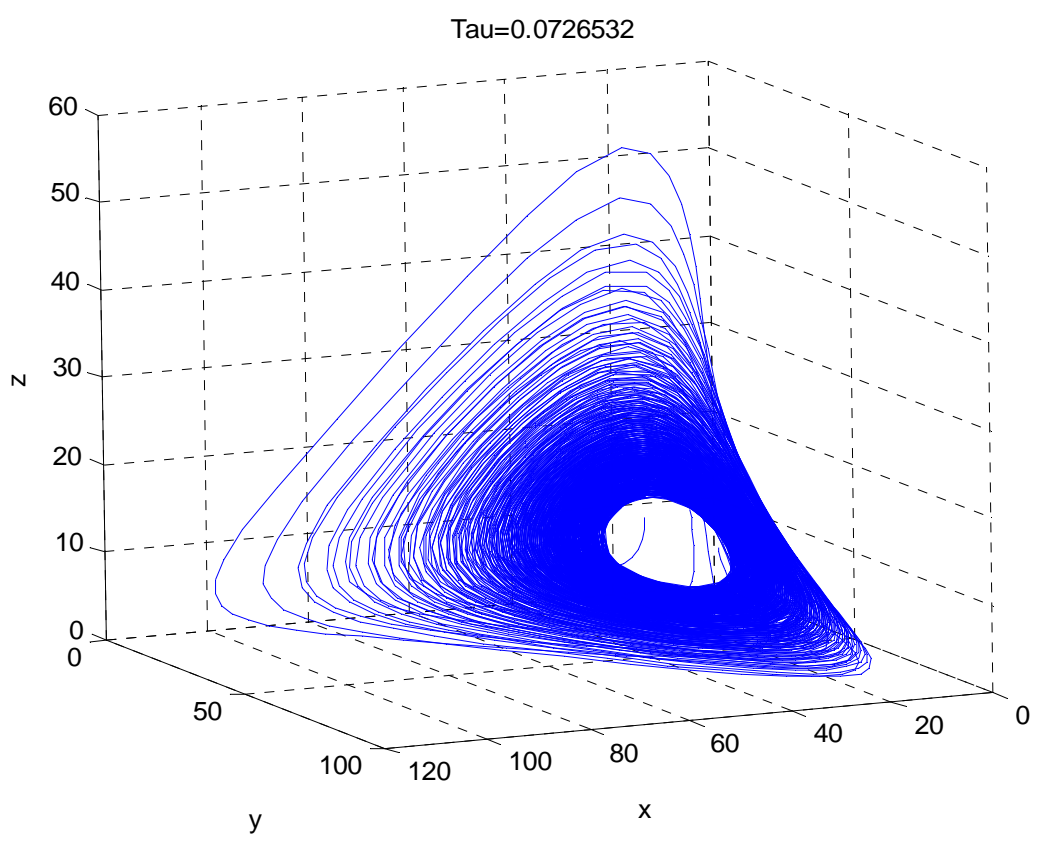

Fig.11. For $\tau=\tau_{0}=0.0726532$, there is a limit cycle near $\mathrm{E}_{\mathrm{xyz}}$.

In most of the ecosystems, population of one species does not respond instantaneously to the interactions with other species. To incorporate this idea in modeling approach, the time delay models have been developed. Our result indicates the fact that a sufficient large time delay has ability to destabilize the model system. Considering gestation delay as a bifurcation parameter we have shown that the system undergoes Hopf-bifurcation as ' $\tau$ ' passes through its critical value $\tau_{0}$ from lower to higher and individual population exhibit small amplitude oscillations around their steady-state value.

Appendix. Liu (1994), derived a criteria of Hopf bifurcation without using the eigenvalues of the variational matrix of the interior equilibrium point. We specify below the Liu's criterion.

Liu's criterion: If the characteristic equation of the interior equilibrium point is given by, $\lambda^{3}+a_{1}(\theta) \lambda^{2}+a_{2}(\theta) \lambda+a_{3}(\theta)=0$, where $a_{1}(\theta), \Delta(\theta)=a_{1}(\theta) a_{2}(\theta)-a_{3}(\theta), a_{3}(\theta)$ are smooth function of $\theta$ in an open interval about $\theta^{*} \in R \quad$ such that

(I) $a_{1}\left(\theta^{*}\right)>0, \Delta\left(\theta^{*}\right)=0, a_{3}\left(\theta^{*}\right)>0$

(II) $\left.\frac{d \Delta}{d \theta}\right|_{\theta=\theta^{*}} \neq 0$, then a simple Hopf bifurcation occurs at $\theta=\theta^{*}$.

\section{References}

Abrams P. A and Ginzburg L. R., 2000. The nature of predation: prey dependent, ratio dependent or neither. Trends in Ecology and Evolution, Vol.15, pp. 337-341.

Akcakaya H. R., Arditi R. and Ginzburg L. R., 1995. Ratio-dependent predition: an abstraction that works. Ecology, Vol.76, pp. 995-1004.

Arditi R., Ginzburg L. R. and Akcakaya H. R., 1991. Variation in plankton density among lakes: a case of ratio dependent models. American Naturalist, Vol. 138, pp. $1287-1296$.

Arditi R. and Saiah H., 1992. Empirical evidence of the role of heterogeneity in ratio dependent consumption. Ecology, Vol.73, pp. 1544-1551.

Braza P. A., 2008. A dominant predator, a predator, and a prey. Mathematical Biosciences and Engineering, Vol.5, No. 1 , pp. 61-73.

Dubey B., Upadhyay R. K., 2004. Persistence and extinction of one prey and two predator system, J. Nonlinear Analysis. Modelling and Control, Vol. 9, No. 4, pp. 307-329.

Freedman H.I., Waltman P., 1984. Persistence in model of three interacting predator-prey population. Math. Biosci., Vol.68, pp. 213-231. 
Gao H., Wei H., Sun W. and Zhai X., 2000. Functions used in biological models and their influence on simulations. Indian Journal of Marine Science, Vol.29, pp. 230-237.

Gard T. C. and Hallam T. G., 1997. Persistence in food webs -1, Lotka -Volterra food chains. Bull. Math. Biol., Vol. 41, pp. 877891.

Hafbauer J., 1981. A general cooperation theorem for hyper cycles. Monatsh Math., Vol. 91, pp. 233-240.

Hale J. K., 1969. Ordinary Differential Equations, Johan Wiley \& Sons, New York.

Hsu S. B., Hwang T. W., Kuang Y., 2001. Rich dynamics of a ratio-dependent one prey - two predators model. J. Math. Biol., Vol. 43, pp. 377-396.

Hudson P. J., Dobson A. P. and Newborn D., 1998. Prevention of population cycles by parasite removal. Science, Vol. 282, pp. 2256-2258.

Hutson V. and Vickers G. T., 1983. A criterion for permanent coexistence of species with an application to two prey, one predator system. Math. Biosci., Vol.63, pp. 253-269.

Kesh D., Sarkar A. Kand., Roy A. B., 2000. Persistence of two prey - one predator system with ratio dependent predator influence. Math. Appl. Sci., Vol.23, pp. 347-356.

Liu W. M., 1994. Criterion of Hopf bifurcation without using eigenvalues. J. Math. Anal. Appl., Vol.182, pp.250-256.

Martin A. and Ruan S., 2001. Predator-prey models with delay and prey harvesting. J. Math. Biol., Vol.43 pp. 247-267.

Kar T. K. and Chaudhury K. S., 2004. Harvesting in a two-prey one-predator fishery. ANZIAM J., Vol.45, pp. 443-456.

Steele J. H. and Henderson E. W., 1992. The role of predation in plankton models Journal of Plankton Research. Vol. 14, pp.157172.

Zhang J. Fan M. and Kuang Y., 2006. Rabbits Killing birds revisited. Mathematical Biosciences, Vol.203, pp.100 - 123.

\section{Acknowledgement}

Research of T. K. Kar is supported by the Council of Scientific and Industrial Research (C S I R), India (Grant no. 25(0160)/ 08/ EMR-II dated 17.01.08)

\section{Biographical notes}

Dr. T. K. Kar is an Associate Professor at the Department of Mathematics, Bengal Engineering and Science University, Shibpur, in India. His research interests include Dynamical systems, stability and bifurcation theory, population dynamics, mathematical modeling in ecology and epidemiology, management and conservation of fisheries, bioeconomic modeling of renewable resources. He wrote around 60 academic papers on those topics. He also supervised several students of master and doctor degree.

Ashim Batabyal is an assistant teacher of Mathematics, Bally Nischinda Chittaranjan vidyalaya, Howrah, in India. He is currently doing his Ph.D. under the guidance of Dr. T. K. Kar in the Department of Mathematics, Bengal Engineering and Science University, Shibpur, India. His research topic is "Mathematical modelling on the dynamics of ecological systems with special emphasis on epidemiological problems". He has obtained his post graduate degree in Mathematics from the University of Burdwan in 1995.

Received January 2010

Accepted March 2010

Final acceptance in revised form April 2010 